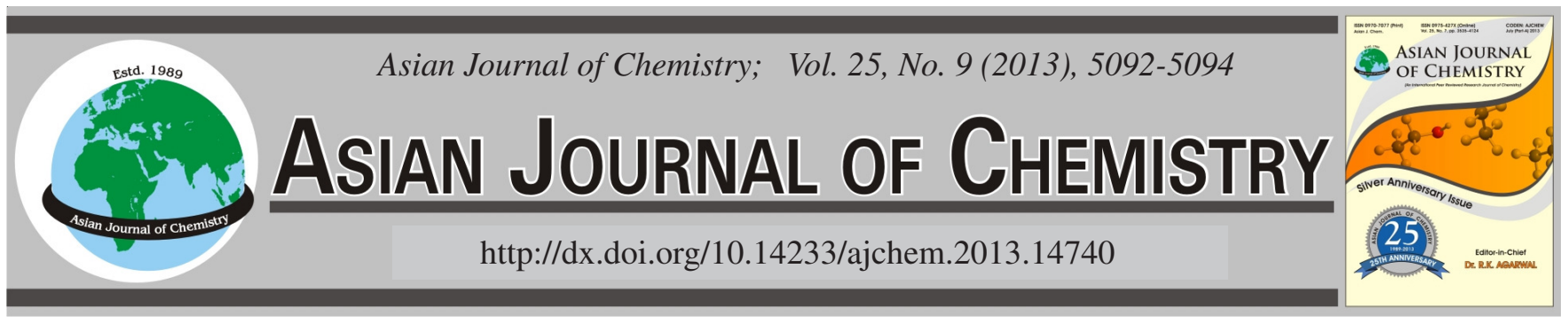

\title{
Analysis of Essential Elements of Three Different Varieties of Saudi Arabian Date Palm (Phoenix dactylifera)
}

\author{
Kahkashan Perveen* ${ }^{*}$ Najat A. Bokhari and Dina A. W. Soliman
}

Department of Botany and Microbiology, King Saud University, P.O. Box 22452, Riyadh-11495, Kingdom of Saudi Arabia

*Corresponding author: E-mail: kperveen@ksu.edu.sa

\begin{abstract}
The elements present in seeds and leaves of three varieties of Saudi Arabian date palm (Phoenix dactylifera) were analyzed by inductively coupled plasma optical emission spectroscopy (ICP-OES). In general it has been found that all the three varieties contain sound but variable amount of element content. Potassium was found to be in abundance in var. Barhee and Sukri, whereas in var. Rothana calcium content was highest. Elements $\mathrm{Ca}, \mathrm{Mg}, \mathrm{Fe}$ and $\mathrm{Mn}$ were observed to be higher in leaves of all three varieties than respective seeds. However reverse was found true for $\mathrm{P}$ and $\mathrm{Zn}$ content. It was observed that sodium content was higher in the leaves of var. Rothana and Sukri while in var. Barhee it was higher in seeds. The micro element $\mathrm{Cu}$ was found to be highest in seeds of Barhee $(0.008 \mathrm{mg} / \mathrm{g})$. The essential trace element Se was found to be present in quite good amount in all the three varieties of date palm and was highest in the seeds of Rothana $(0.0043 \mathrm{mg} / \mathrm{g})$. The present study clearly indicates the immense potential of $P$. dactylifera to be utilized in development of element supplement.
\end{abstract}

Key Words: Date palm, Element content, Inductively coupled plasma optical emission spectroscopy.

\section{INTRODUCTION}

The date palm is a major fruit tree in most of Arabian Peninsula and it is considered one of the most important co mmercial crops. Dates, the fruits of date palm constitute a substantial part of the diet in the Arabian world. Presently 2000 or more different cultivars of date palm are cultivated worldwide $^{1}$. The beneficial health and nutrition values of date palm, for human and animal consumption have been claimed for centuries $^{2-4}$. Phytochemically, the whole plant contains carbohydrates, alkaloids, steroids, flavonoids, vitamins and tannins. The phenolic profile of the plant revealed the presence of mainly cinnamic acids, flavonoid glycosides and flavanols ${ }^{5,6}$. Four free phenolic acids and nine bound phenolic acids have been tentatively identified ${ }^{7,8}$. The pharmacological studies conducted on $P$. dactylifera indicate the immense potential of this plant in the treatment of conditions such as diarrhea, gastric ulcer, skin disorders, cardiovascular disorder and inflammatory ailments including liver and kidney disorders, microbial and viral infections, cancer. Date palm is considered as a potentially safe and effective plant that has important medicinal values and benefits? .

Plant derived drugs are gaining importance due to their minimal side effects, easy availability and acceptability. Furthermore plant parts are used raw to overcome macro and micro nutrient malnutrition ${ }^{10}$. Most studies on such medicinal plants pertain to their organic contents, viz., essential oils, glycosides, vitamins, alkaloids and other active components and their pharmacological/therapeutic effects. Besides several organic compounds, it is now well established that many trace elements play a vital role in general well-being as well as in the cure of diseases ${ }^{11}$. The leaves of the plants are still used in several countries, for their therapeutic effects. The elements associated with life process have been classified into macro nutrients, which are needed in large amount such as sodium, calcium, magnesium, potassium, chlorine etc. The other category is of those elements which are required in very small amounts, include vanadium, chromium, manganese, iron, cobalt, copper, zinc and molybdenum and the non-metals selenium, fluorine and iodine ${ }^{11}$. Since these trace elements constitute a minute fraction in different parts of the medicinal plants, a sensitive and reliable analytical technique is a prerequisite for obtaining precise and accurate data ${ }^{12}$.

Most of the available literature on element content of date palm deals with fruits rather than vegetative parts such as leaves, though some studies were carried out on role of elements in growth and development of plant ${ }^{13,14}$. The numbers of date palm in the Kingdom of Saudi Arabia are estimated to be over 23.5 million. These trees are estimated to yield about 210,000 tons of fronds. Every year about three million palm trees are pruned and the portion becomes a waste ${ }^{15}$. Thus, the study was planned to find out the possible use of date palm 
leaves as a source of element/mineral supplement. The elements of date palm leaves were determined by inductively coupled plasma-optical emission spectroscopy (ICP-OES).

\section{EXPERIMENTAL}

Collection and storage of date palm leaves: Fresh leaves and dates of three varieties of date palm, Barhee, Sukri and Rothana were kindly provided by Mr. Abdulmohssin AlShamlan from his Al-Shamlan date farm (Onaizah, Al-Qassim). Samples were labeled and stored at $4^{\circ} \mathrm{C}$ in polythene bags till they were processed.

Sample preparation: Surface contaminants of the leaf samples were removed by washing twice with deionized water and then with deionized double distilled water. The leaves were air dried in a clean drying chamber for 15 days. Whereas seeds/ pits were manually removed from the fruits and samples were washed with distilled water and were dried at $40{ }^{\circ} \mathrm{C}$ for 2 days in an oven (Memmert, Germany). The dried leaves and seeds/ pits samples were separately ground well into a fine powder with the help of mill (IKA werke, GMBH \& Co., Germany). The powder was stored in air sealed plastic containers at room temperature until analyzed.

Digestion and analysis of sample: Powdered leaves and seeds/pits samples $(0.5 \mathrm{~g})$ were separately digested with conc. sulphuric acid $(3.5 \mathrm{~mL})$ and $30 \%$ hydrogen peroxide $(3.5 \mathrm{~mL})$ by heating at $25^{\circ} \mathrm{C}$ for $0.5 \mathrm{~h}$. After cooling, $30 \%$ hydrogen peroxide $(1 \mathrm{~mL})$ was added and filtered to get the clear solution. The filtrate was diluted to $20 \mathrm{~mL}$ with deionized distilled water $^{16}$. The digested samples were analyzed to determine the content of calcium, magnesium, phosphorus, potassium, iron, copper, zinc, manganese, sodium and selenium by inductively coupled plasma optical emission spectroscopy, Perkin-Elmer Optima 4300 DV ICP-OES.

\section{RESULTS AND DISCUSSION}

The results of the analysis of essential element content of leaves and seeds/pits of three varieties of Saudi Arabian date palm showed the presence of $\mathrm{Ca}, \mathrm{Mg}, \mathrm{P}, \mathrm{K}, \mathrm{Na}, \mathrm{Cu}, \mathrm{Zn}, \mathrm{Mn}$ and Se (Table-1). It was observed that potassium was the most abundant element in the leaves and seed/pits of var. Barhee and Sukrim whereas $\mathrm{Ca}$ was found in relatively high concentration in var. Rothana. The other elements were found in various proportions in the leaves and seeds/pits of three varieties of date palm. It has been observed that the sodium content was higher in the leaves of Rothana and Sukri (0.1059 and $0.1396 \mathrm{mg} / \mathrm{g}$, respectively) while in var. Barhee it was higher in seeds $(7.8146 \mathrm{mg} / \mathrm{g})$.

Calcium contents was highest in the leaves and seeds/pits var. of Barhee (5.268 and $0.3396 \mathrm{mg} / \mathrm{g}$, respectively). Phosphorus and zinc were relatively high in seeds/pits of var. Rothana (1.360 and $0.0214 \mathrm{mg} / \mathrm{g}$, respectively) while the level of magnesium was highest in leaves of var. Rothana (2.214 $\mathrm{mg} / \mathrm{g}$ ). Leaves of all three varieties of $P$. dactylifera contain significant amount of iron and it was highest in leaves of var. Barhee $(0.2183 \mathrm{mg} / \mathrm{g})$. These varieties of date palm also have different amount of $\mathrm{Mn}, \mathrm{Cu}$ and $\mathrm{Se}$. Manganese was higher in the leaves than seeds in all three varieties and it was same in leaves of var. Rothana and Barhee $(0.0132 \mathrm{mg} / \mathrm{g})$. The micro element $\mathrm{Cu}$ was found to be highest in seeds of Barhee $(0.008$ $\mathrm{mg} / \mathrm{g}$ ). The essential trace element Se was found to be present in quite good amount in all three varieties of date palm and was highest in the seeds of Rothana $(0.0043 \mathrm{mg} / \mathrm{g})$.

The ratio of $\mathrm{K} / \mathrm{Na}$ in three varieties of date palm is presented in Fig. 1. It was observed that $\mathrm{K} / \mathrm{Na}$ ratio was higher in leaves of var. Barhee and Sukri, whereas in var. Rothana the $\mathrm{K} / \mathrm{Na}$ ratio was higher in seeds. However the $\mathrm{Fe} / \mathrm{Zn}$ ratio was higher in leaves of all date palm than seeds (Fig. 2).

The results revealed that the date palm leaves and seeds/ pits, depending upon the variety contain significant but quite variable amounts of essential elements. Our results are in agreement with a study of Kahtani et al. ${ }^{17}$ they determined the leaf mineral composition of seventeen date palm cultivars and found a significant variation in mineral content between the cultivars and growth stages. Similarly, Gassim et al ${ }^{18}$ analyzed the leaf mineral composition (N, K, P, Ca, Mg, Na, Fe, Mn, $\mathrm{Zn}$ and $\mathrm{Cu}$ ) of four date cultivars i.e., Khalas, Ruzeiz, Shieshi and Hatami. They observed that cultivars varied significantly with respect to mineral content. In a study the mineral ion composition of six different cultivars of Bahraini date palm seeds (Khalas, Murzban, Khunaizi, Khawajah, Khasaib Asfor and Khaseeb) were analyzed using flame atomic absorption spectroscopy (AA and ICPS). The essential bulk metal ions in the six cultivars were found to be dominant, where $\mathrm{K}^{+}$was the highest and $\mathrm{Ca}^{2+}$ was the lowest ${ }^{13}$.

TABLE-1

ELEMENTS CONTENT IN THE SEEDS AND LEAVES OF $P$. dactylifera VAR. ROTHANA, BARHEE AND SUKRI

\begin{tabular}{|c|c|c|c|c|c|c|}
\hline \multirow{4}{*}{ Elements } & \multicolumn{6}{|c|}{ Varieties } \\
\hline & \multicolumn{2}{|c|}{ Rothana } & \multicolumn{2}{|c|}{ Barhee } & \multicolumn{2}{|c|}{ Sukri } \\
\hline & Seed & Leaves & Seed & Leaves & Seed & Leaves \\
\hline & \multicolumn{2}{|c|}{$\mathrm{mg} / \mathrm{g}$} & \multicolumn{2}{|c|}{$\mathrm{mg} / \mathrm{g}$} & \multicolumn{2}{|c|}{$\mathrm{mg} / \mathrm{g}$} \\
\hline Calcium & $0.2228 \pm 0.00057 *$ & $4.092 \pm 0.00061$ & $0.3396 \pm 0.0004$ & $5.268 \pm 0.0005$ & $0.1501 \pm 0.0001$ & $4.822 \pm 0.00051$ \\
\hline Magnesium & $0.9259 \pm 0.0009$ & $2.214 \pm 0.0005$ & $0.8773 \pm 0.0003$ & $2.010 \pm 0.00058$ & $0.7350 \pm 0.0002$ & $2.190 \pm 0.0005$ \\
\hline Sodium & $0.0897 \pm 0.00041$ & $0.1059 \pm 0.00028$ & $0.1569 \pm 0.00016$ & $0.1226 \pm 0.00023$ & $0.07375 \pm 0.0001$ & $0.1396 \pm 0.00015$ \\
\hline Potassium & $2.8343 \pm 0.00115$ & $2.068 \pm 0.00048$ & $2.699 \pm 0.00003$ & $7.8146 \pm 0.00079$ & $4.0047 \pm 0.00063$ & $7.885 \pm 0.0006$ \\
\hline Phosphorus & $1.360 \pm 0.0010$ & $1.015 \pm 0.00055$ & $1.222 \pm 0.0005$ & $0.9375 \pm 0.00025$ & $1.1825 \pm 0.0005$ & $0.8550 \pm 0.0005$ \\
\hline Iron & $0.0225 \pm 0.0005$ & $0.1422 \pm 0.00015$ & $0.0549 \pm 0.0001$ & $0.2183 \pm 0.00036$ & $0.0212 \pm 0.0002$ & $0.1106 \pm 0.0002$ \\
\hline Zinc & $0.0214 \pm 0.0004$ & $0.013 \pm 0.00006$ & $0.0211 \pm 0.00025$ & $0.0150 \pm 0.00012$ & $0.0195 \pm 0.0001$ & $0.0131 \pm 0.0001$ \\
\hline Copper & $0.0077 \pm 0.0002$ & $0.0069 \pm 0.00006$ & $0.008 \pm 0.0001$ & $0.0061 \pm 0.00021$ & $0.064 \pm 0.0001$ & $0.0070 \pm 0.00006$ \\
\hline Manganese & $0.0082 \pm 0.0002$ & $0.0132 \pm 0.00015$ & $0.0062 \pm 0.0002$ & $0.0132 \pm 0.0001$ & $0.0058 \pm 0.0001$ & $0.0108 \pm 0.0001$ \\
\hline Selenium & $0.0043 \pm 0.0003$ & $0.0035 \pm 0.00006$ & $0.0004 \pm 0.0$ & $0.0027 \pm 0.00006$ & $0.0005 \pm 0.0$ & $0.0037 \pm 0.0002$ \\
\hline
\end{tabular}

$*$ Values represent the mean \pm SD of three replicates. 


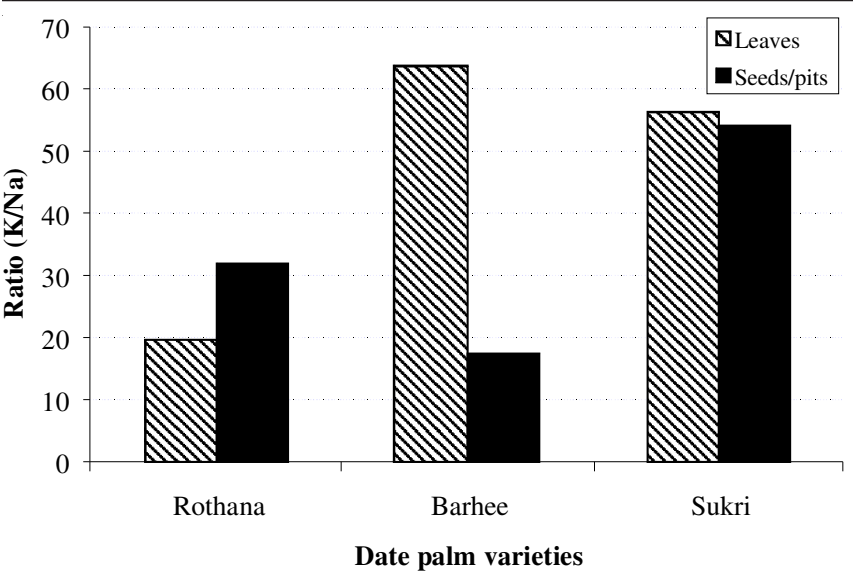

Fig. 1. K/Na ratio of leaves and seeds/pits of P. dactylifera var. Rothana, Barhee and Sukri

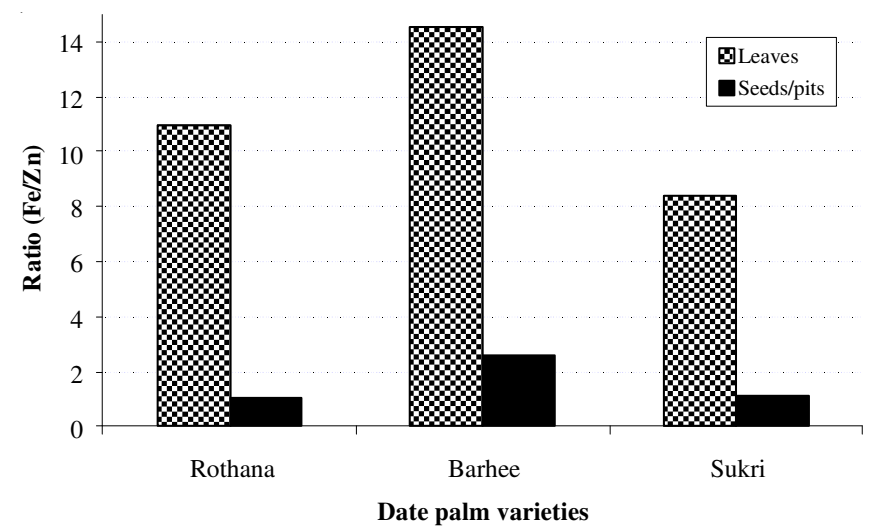

Fig. 2. Fe/Zn ratio of leaves and seeds/pits of P. dactylifera var. Rothana, Barhee and Sukri

It has been found that calcium content was highest in the leaves and seeds/pits var. of Barhee. In plants, calcium is taken up in the ionized form (as $\mathrm{Ca}^{2+}$ ); the leafy parts are relatively high in calcium and low in phosphorus, whereas, the reverse is true of the seeds ${ }^{19}$. The higher Ca content in the leaves and seeds/pits of Barhee suggests its possible use to overcome deficiency of $\mathrm{Ca}$. The recommended daily dietary allowance of $\mathrm{Ca}$ for children is between 500, 1000 and $800 \mathrm{mg}$ for adults ${ }^{20}$. As the leaves and seeds/pits of the date palm contains good amount of iron it can be utilize in the preparation of iron rich supplements to compensate iron deficiency. These varieties of date palm also have different amount of $\mathrm{Mn}, \mathrm{Cu}$ and Se. Metals manganese, iron, copper and zinc and the non metal selenium are essential trace elements for all forms of life. In humans $\mathrm{Mn}, \mathrm{Fe}, \mathrm{Cu}, \mathrm{Zn}$ and $\mathrm{Se}$ accomplish decisive functions to maintain human health. Deficiency in any of these trace elements leads to undesirable pathological conditions that can be prevented or reversed by adequate supplementation ${ }^{11}$.
In this study, the positive correlation was observed between $\mathrm{Na}$ and $\mathrm{K}$ as well as $\mathrm{Fe}$ and $\mathrm{Zn}$ concentrations in different varieties of date palm. Thereby it indicates the inter-connected physiological mechanisms for their uptake/translocation in the leaves. This is in the line of previous report which has suggested interrelationship of essential elements like K, Na, $\mathrm{Fe}$ and $\mathrm{Zn}^{12}$. The relationship between elemental content and curative capability is yet to be established; however such studies are important for understanding the pharmacological action of medicinal plants. The data obtained in the present study will be helpful in understanding the role of element content in categorizing the varieties of $P$. dactylifera as well as in the development of supplements.

\section{ACKNOWLEDGEMENTS}

The authors extended their appreciation to the Deanship of Scientific Research at King Saud University for funding the work through the research group project No. RGP-VPP- 066.

\section{REFERENCES}

1. S. Al-Hooti, J.S. Sidhu and H. Qabazard, Plant Foods Human Nutr., 50, 101 (1997).

2. P.K. Vayalil, J. Agric. Food Chem., 50, 610 (2002).

3. A. Tahraoui, J. El-Hilaly, Z.H. Israili and B. Lyoussi, J. Ethnopharmacol., 110, 105 (2007).

4. B. Al-Gboori and V. Krepl, Agric. Trop. Subtrop., 43, 341 (2010).

5. V.H.W. Dowson, Food and Agriculture Organization of the United Nations, p. 35 (1982).

6. F. Biglari, F.M.K. Abbas and M.E. Azhar, Food Chem., 107, 1636 (2008).

7. A.C. Ziouti, E.L. Modafar, A.S. Fleuriet, E.L. Boustani and J.J. Macheix, Biol. Plant., 38, 451 (1996).

8. Y.J. Eong, F.A. Hong, B. Tomas, A. Adel, S. Kader and E. Alyson, J. Agric. Food Chem., 54, 2405 (2006).

9. M.S. Baliga, B.R. Baliga, S.M. Kandathil, H.P. Bhat and P.K. Vayalil, Food Res. Int., 44, 1812 (2011).

10. H.K. Bakhru, Herbs that Heal Natural Remedies for Good Health, Orient Paperbacks, Division of Vision Book Pvt. Ltd. New Delhi, pp. 65-68 (1998).

11. C.G. Fraga, Mol. Asp. Med., 26, 235 (2005).

12. R. Lokhande, P. Singare and M. Andhale, Health Sci. J., 4, 157 (2010).

13. A.Y.A. Mohamed and A.S.H. Khamis, J. Agric. Food Chem., 52, 6522 (2004).

14. J. Saleh, Int. J. Plant Prod., 3, 57 (2009).

15. Anonymous, Ministry of Agriculture, Riyadh, Kingdom of Saudi Arabia, No. 22 (2009).

16. R.L. Westrman, J.V. Baird, N.W. Christensen, P.E. Fixen and D.A. Whitney, Soil Testing and Plant Analysis, edn. 3, SSSA, Book Series No. 3, Guilford Rd., Madison, WI USA, pp. 404-410 (1990).

17. M.S. Al-Kahtani, G. Hussain, N. El-Dairi and A.S. Al-Ghamdi, Second Symposium on Date Palm, pp. 217-224 (1986).

18. A.A. Gassim, G.M. El-Hassan and A.A. Khateeb, Second Symposium on Date Palm, pp. 377-384 (1986).

19. V.M. Merck, The Merck Veterinary Manual, Published by Merck and Co., Inc., Rahway, New Jersey, USA, edn. 6, p. 1677 (1986).

20. P. Charles, J. Int. Med., 231, 161 (1992). 